\title{
The Control of the Synthesis of Isocitrate Lyase in a Thermophilic Bacillus
}

\author{
By MANSEL W. GRIFFITHS* \\ Department of Biochemistry, University of Leicester, Leicester
}

(Received 27 September 1978; revised 8 December 1978)

\begin{abstract}
From a strain of Bacillus stearothermophilus, devoid of active pyruvate carboxylase, a mutant (NG-15) was selected that grew on acetate in the presence of glucose. This mutant differed from its parent organism in possessing high activities of isocitrate lyase when grown on all carbon sources tested except nutrient broth, in possessing unusually low activities of $\mathrm{NADP}^{+}$-dependent isocitrate dehydrogenase and in containing increased amounts of isocitrate. Revertants of mutant NG-15 which regained the ability to synthesize active pyruvate carboxylase also synthesized isocitrate lyase and isocitrate dehydrogenase to the same extent as the wild-type strain. These results suggest that the regulatory mechanism for the synthesis of isocitrate lyase in the thermophile may be different from that in mesophilic bacilli.
\end{abstract}

\section{INTRODUCTION}

Isocitrate lyase is a key enzyme of the glyoxylate cycle (Kornberg \& Madsen, 1957, 1958; Kornberg \& Krebs, 1957). The synthesis of this enzyme in Escherichia coli appears to be under the control of a metabolite repressor, thought to be phosphoenolpyruvate or pyruvate (Kornberg, 1965, 1966), but this may not be so in all organisms (Herman \& Bell, 1970; Higgins \& Sariaslani, 1973). Like many other micro-organisms, a thermophilic strain of Bacillus isolated by Epstein \& Grossowicz (1969) is induced to synthesize isocitrate lyase during growth on acetate (Sundaram \& Kornberg, 1969; Griffiths \& Sundaram, 1973). The growth on acetate of mutants of this thermophile that lack pyruvate carboxylase is inhibited by glucose. Further mutants can be isolated which, though still devoid of pyruvate carboxylase, are resistant to the growth inhibition brought about by glucose. Many such mutants are constitutive for isocitrate lyase (Sundaram, 1973). However, one such mutant, designated NG-15, has been found which may not be truly constitutive for the enzyme. The properties of this mutant are described here and the results are discussed in relation to a possible regulatory system for isocitrate lyase synthesis in this thermophilic strain of Bacillus.

\section{METHODS}

Isolation of mutant. A mutant designated PC-2, devoid of active pyruvate carboxylase, was isolated from wild-type cells of a thermophilic strain of Bacillus (Sundaram, 1973). This organism was used as a source of further mutants which were not inhibited by glucose when they were grown on acetate as carbon source. Cultures of strain PC-2 were grown in nutrient broth and were inoculated into flasks containing salts (Sundaram et al., 1969), supplemented with biotin $\left(0 \cdot 1 \mu \mathrm{g} \mathrm{ml}^{-1}\right)$ and sodium acetate (50 mM). The cultures were harvested in the mid-exponential phase of growth by centrifuging at $10000 \mathrm{~g}$ for $10 \mathrm{~min}$ at $18{ }^{\circ} \mathrm{C}$. The cells were resuspended to about $0.1 \mathrm{mg}$ dry mass $\mathrm{ml}^{-1}$ in the salts solution and samples $(0.05$ to $0.2 \mathrm{ml})$ of the suspensions were spread on to plates containing a mixture of sodium acetate $(50 \mathrm{~mm})$, glucose $(10 \mathrm{~mm})$, biotin $\left(0 \cdot 1 \mu \mathrm{g} \mathrm{ml}^{-1}\right)$ and nutrient broth $\left(160 \mu \mathrm{g} \mathrm{ml}^{-1}\right)$, solidified with $1.5 \%(\mathrm{w} / \mathrm{v})$ agar. A crystal of $5^{\prime}-$ methyl-5'-nitrosoguanidine was placed in the middle of each plate and the plates were incubated at $55^{\circ} \mathrm{C}$ for

* Present address: The Hannah Research Institute, Ayr, Scotland KA6 5HL. 
$36 \mathrm{~h}$. A clone, designated NG-15, was obtained which was able to grow on the acetate/glucose plates. This was purified by repeated restreaking on acetate/glucose plates.

Growth of the organism and preparation of cell-free extracts. The organism was grown and extracts were prepared by lysozyme treatment as described previously (Griffiths \& Sundaram, 1973).

Measurement of enzyme activities. Isocitrate lyase (EC 4.1.3.1) was assayed by the method of Kornberg (1965) as described by Griffiths \& Sundaram (1973). An alternative method was adopted for the assay of isocitrate lyase in inhibition studies with pyruvate and phosphoenolpyruvate, both of which react with phenylhydrazine to form hydrazones. In this case, the assay method of John \& Syrett (1968) was employed.

Pyruvate carboxylase (EC 6.4.1.1) was assayed at $45^{\circ} \mathrm{C}$ by measuring the ${ }^{14} \mathrm{C}$ fixed from $\mathrm{KH}^{14} \mathrm{CO}_{3}$ or $\mathrm{Na}_{2}{ }^{14} \mathrm{CO}_{3}$ with pyruvate as substrate (Sundaram et al., 1969).

The activity of $\mathrm{NADP}^{+}$-dependent isocitrate dehydrogenase (EC 1.1.1.42) was determined by the method of Cleland et al. (1969).

The method of Dixon \& Kornberg (1959) was used to assay the activity of malate synthase (EC 4.1.3.2).

Aconitase (aconitate hydratase; EC 4.2.1.3) activity was assayed by the method of Racker (1950).

Except where stated, all the assays were carried out at $30^{\circ} \mathrm{C}$. Protein concentrations were determined by the method of Lowry et al. (1951).

Preparation of cultures for the measurement of metabolite levels. Cultures were grown for six or more generations and samples for analysis were taken when the cultures had reached a density of approximately $0 \cdot 1$ to $0.2 \mathrm{mg}$ dry mass $\mathrm{ml}^{-1}$. Dry mass was measured as absorbance at $680 \mathrm{~nm}$, an $A_{680}$ of 1.0 corresponding to $0.33 \mathrm{mg}$ dry mass $\mathrm{ml}^{-1}$ (Harris \& Kornberg, 1972). The cells were harvested by rapid filtration of 30 to $50 \mathrm{ml}$ culture on to a Millipore filter ( $47 \mathrm{~mm}$ diam., $0.45 \mu \mathrm{m}$ pore size) with suction. The filters were then treated with $\mathrm{HClO}_{4}$ as described by Lowry et al. (1971).

Measurement of isocitrate concentration in extracts. Isocitrate present in extracts obtained by the above procedure was determined by mixing portions of them with $100 \mu$ mol imidazole/acetate buffer $(\mathrm{pH} 7 \cdot 0)$, $0.1 \mu \mathrm{mol} \mathrm{MnCl}_{2}, 0.1 \mu \mathrm{mol}$ NADP, $2.5 \mu \mathrm{g}$ isocitrate dehydrogenase (from pig heart, Sigma) and water to $1 \mathrm{ml}$. The initial $A_{340}$ was measured spectrophotometrically and again $5 \mathrm{~min}$ after addition of the enzyme. The concentration of isocitrate was calculated from the amount of NADPH formed, a $\Delta A_{340}$ of 0.622 being taken as equivalent to $0.1 \mu \mathrm{mol}$ isocitrate.

Measurement of glyoxylate concentration in extracts. The method of Klotzsch \& Bergmeyer(1965) was used. The glyoxylate present in bacterial extracts was determined by mixing portions of them with $33 \mu$ mol phosphate buffer (pH 6.4), 0.24 $\mu \mathrm{mol} \mathrm{NADH,} 20 \mu \mathrm{g}$ glyoxylate reductase (EC 1.1.1.26; Boehringer) and water to $1 \mathrm{ml}$. The decrease in $\boldsymbol{A}_{\mathbf{3 4 0}}$ was measured spectrophotometrically after addition of the enzyme. The concentration of glyoxylate was calculated from the amount of NAD formed, $\Delta A_{340}$ of 0.622 being taken as equivalent to $0 \cdot 1 \mu \mathrm{mol}$ glyoxylate.

Chemicals. Most biochemicals were from Sigma; coenzyme A and NADH were from Boehringer; FolinCiocalteu reagent and lysozyme were from BDH; 5'-methyl-5'-nitrosoguanidine was from Koch-Light; radiochemicals were from The Radiochemical Centre, Amersham. Acetyl-coenzyme A was prepared from coenzyme A and acetic anhydride (Cazzulo et al., 1970).

\section{RESULTS}

\section{Growth of thermophile mutants on various carbon sources}

Mutant NG-15 was selected for its ability to grow on acetate in the presence of glucose. The parent organism, PC-2, was unable to grow on this medium as it lacked pyruvate carboxylase activity (Sundaram, 1973). Addition of glucose to wild-type cultures or cultures of strain NG-15 growing at $55^{\circ} \mathrm{C}$ on acetate as sole carbon source resulted in an immediate acceleration in their growth rates. The mean generation time for the wild-type decreased from $120 \mathrm{~min}$ for growth on acetate to $73 \mathrm{~min}$ for growth on acetate plus glucose. Similarly, for strain NG-15 the mean generation time decreased from 124 min for growth on acetate to $98 \mathrm{~min}$ for growth on acetate in the presence of glucose. In contrast, addition of glucose to a culture of strain PC-2 growing on acetate caused growth to stop after $1 \mathrm{~h}$. This was probably due to inhibition of isocitrate lyase activity by the $\mathrm{C}_{3}$ compounds formed from glucose (Kornberg \& Smith, 1969) and, in agreement with this view, could be reversed by the further addition of 10 mM-glyoxylate. Growth of strain PC-2 on acetate was also inhibited by adding pyruvate or lactate, but this was not so for strain NG-15.

Because of its lack of pyruvate carboxylase activity, mutant PC-2 was unable to grow on glucose as sole carbon source. Its mutant NG-15 was also devoid of pyruvate carboxylase 
Table 1. Enzyme activities in extracts of thermophiles grown on acetate as the sole carbon source

Extracts were made from cells grown to late-exponential phase and assayed at $30^{\circ} \mathrm{C}$ as described

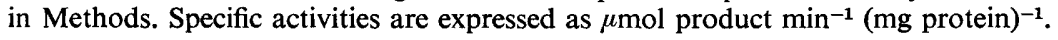

Specific activity in extracts of:

\begin{tabular}{|c|c|c|c|c|}
\hline Enzyme & Wild-type & $\begin{array}{l}\text { Strain } \\
\text { PC-2 }\end{array}$ & $\begin{array}{l}\text { Strain } \\
\text { NG-15 }\end{array}$ & $\begin{array}{c}\text { Strain } \\
\text { R-9 }\end{array}$ \\
\hline Aconitase & 0.59 & 0.53 & 0.82 & 0 \\
\hline Isocitrate lyase & 0.20 & $0 \cdot 21$ & 0.22 & 0.09 \\
\hline Malate synthase & 0.68 & 0.88 & 0.74 & - \\
\hline $\begin{array}{l}\mathrm{NADP}^{+} \text {-dependent } \\
\text { isocitrate dehydrogenase }\end{array}$ & 0.078 & 0.082 & 0.003 & 0.082 \\
\hline Pyruvate carboxylase & $0 \cdot 109$ & 0.001 & 0.001 & 0.051 \\
\hline
\end{tabular}

-, Not tested.

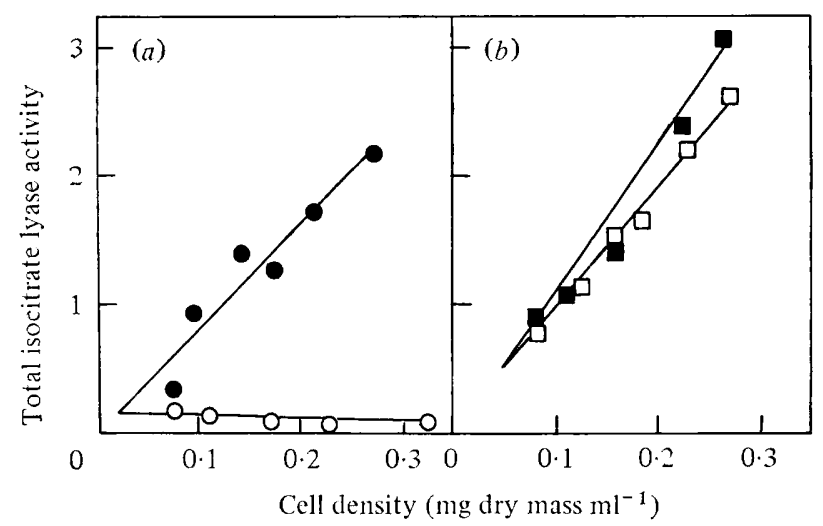

Fig. 1. Effect of glucose addition to acetate-grown cells on the rate of isocitrate lyase synthesis in strains of the thermophile. Samples were removed at various times throughout the growth cycle from cultures of wild-type $(a)$ and strain NG-15 $(b)$ growing on acetate $(\boldsymbol{\sigma}, \boldsymbol{a})$ or on acetate in the presence of glucose $(\bigcirc, \square)$. Organisms were harvested and cell-free extracts were prepared and assayed for isocitrate lyase activity as described in Methods. Total isocitrate lyase activity is expressed as the product of the specific activity of the enzyme in the extract [ $\mu$ mol glyoxylate produced $\min ^{-1}(\mathrm{mg} \text { protein })^{-1}$ ] and cell density [mg dry mass (ml culture) ${ }^{-1}$.

(Table 1), but was able to grow on glucose, albeit slowly, after preincubation on acetate medium. Presumably the glyoxylate cycle could function as the anaplerotic route under these conditions in mutant NG-15, although it could not do so in the parent organism.

Both PC-2 and NG-15 mutants grew on intermediates of the tricarboxylic acid cycle, such as succinate and fumarate, at rates similar to those of the wild-type organism on the same substrates.

\section{Synthesis of isocitrate lyase during growth on various substrates}

Unlike the wild-type organism, strain NG-15 continued to synthesize isocitrate lyase when growing on acetate in the presence of glucose (Fig. 1). By plotting the total activities of isocitrate lyase (defined as the product of the cell density of the culture and the specific activity of the enzyme in extracts of cells harvested at those densities) in extracts of the wild-type organism and mutant NG-15 against the cell densities at which the samples were taken, the rates of induced synthesis of the enzyme in these organisms could be calculated (Monod, 1956).

The activities of isocitrate lyase in the wild-type and mutant strains of the thermophile 
Table 2. Isocitrate lyase activity in extracts of thermophiles grown on various carbon sources

Cells were grown to late-exponential phase on the appropriate carbon source and harvested by centrifugation. The isocitrate lyase activity present in the extracts was determined at $30^{\circ} \mathrm{C}$ as described in Methods. Values are $\mu$ mol glyoxylate formed $\mathrm{min}^{-1}$ (mg protein) ${ }^{-1}$.

Isocitrate lyase activity in extracts of :

$\begin{array}{lccccc} & & \text { Strain } & \text { Strain } & \text { Strain } & \text { Strain } \\ \text { Carbon source } & \text { Wild-type } & \text { PC-2 } & \text { NG-15 } & \text { R-9 } & \text { NG-35 } \\ \text { Acetate } & 0.196 & 0.213 & 0.217 & 0.092 & 0.531 \\ \text { Acetate+glucose } & 0.001 & \text { NG } & 0.205 & 0.013 & - \\ \text { Glucose } & 0.002 & \text { NG } & - & - & 0.161 \\ \text { Citrate } & 0.166 & \text { NG } & - & - & - \\ \text { Succinate } & 0.057 & 0.067 & 0.115 & - & 0.196 \\ \text { Fumarate } & 0.007 & 0.037 & 0.372 & 0.002 & - \\ \text { Malate } & 0.001 & - & 0.196 & 0.008 & - \\ \text { Nutrient broth } & 0.003 & 0.018 & 0.016 & - & 0.137\end{array}$

NG, No growth; -, not tested.

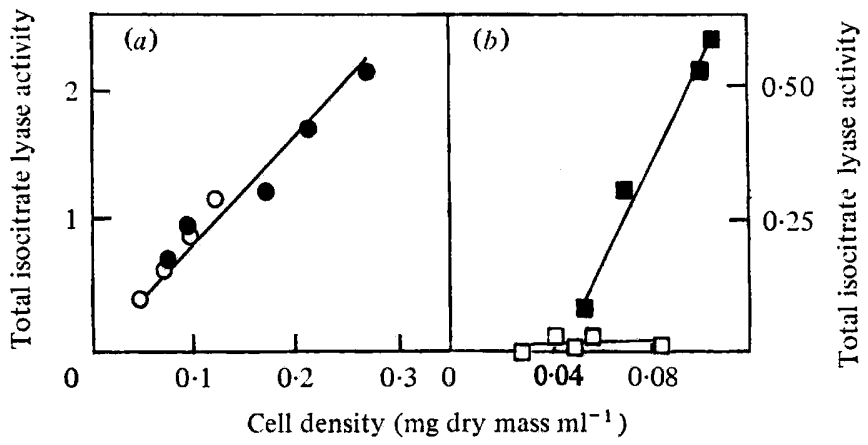

Fig. 2. Synthesis of isocitrate lyase by wild-type cells of the thermophile and Bacillus licheniformis during growth on citrate. Cells of the wild-type strain of the thermophile $(a)$ and the mesophile $B$. licheniformis A5 $(b)$ were grown on salts/acetate $(\mathbf{O}, \mathbf{\square})$ or salts/citrate $(O, \square)$ media. Samples of the cultures were removed at intervals and the cells were harvested. Cell-free extracts were prepared and assayed for isocitrate lyase activity. The total isocitrate lyase activity was plottedagainst the cell density of the culture at the time the cells were removed, as described in Fig. 1.

grown on various carbon sources are shown in Table 2. Mutant NG-15 produced high activities of the enzyme during growth on all the media examined except nutrient broth. In contrast, the parent organism PC-2 contained isocitrate lyase at the same activity as found in wild-type organisms grown on the same substrate. On all media examined, mutant NG-35 also produced isocitrate lyase to a high specific activity. This mutant synthesized isocitrate lyase to a much greater activity than the other strains when grown on acetate.

The activity of isocitrate lyase was low in extracts of wild-type organisms grown on all the media except acetate, citrate and, to a lesser extent, succinate. However, the wild-type strain grew poorly on citrate and the continued synthesis of the enzyme on this medium (Fig. 2a) may indicate a partial relief of catabolite repression consequent upon this poor growth. However, a mesophilic strain of Bacillus (B. licheniformis) also grew slowly on citrate, but without the concomitant synthesis of isocitrate lyase (Fig. $2 b$ ).

The isocitrate lyase activities of mutant NG-15 and the wild-type strain were similar. Both were inhibited by pyruvate and by phosphoenolpyruvate with approximate inhibition constants $\left(K_{\mathrm{i}}\right)$ of $0.8 \mathrm{~mm}$ for phosphoenolpyruvate and $0.5 \mathrm{~mm}$ for pyruvate. 
Table 3. NADP+-dependent isocitrate dehydrogenase activity in extracts of thermophiles grown on various carbon sources

Cells were grown to late-exponential phase on the appropriate substrate. The NADP+-dependent isocitrate dehydrogenase activity present in cell-free extracts was assayed by following the reduction of $\mathrm{NADP}^{+}$at $30^{\circ} \mathrm{C}$. Values are $\mu \mathrm{mol}$ NADP reduced $\mathrm{min}^{-1}(\mathrm{mg} \text { protein })^{-1}$.

\begin{tabular}{|c|c|c|c|c|}
\hline \multirow[b]{2}{*}{ Carbon source } & \multicolumn{4}{|c|}{ Isocitrate dehydrogenase activity in extracts of: } \\
\hline & Wild-type & $\begin{array}{l}\text { Strain } \\
\text { PC-2 }\end{array}$ & $\begin{array}{c}\text { Strain } \\
\text { NG-15 }\end{array}$ & $\begin{array}{c}\text { Strain } \\
\text { R-9 }\end{array}$ \\
\hline Acetate & 0.078 & 0.082 & 0.003 & 0.082 \\
\hline Acetate + glucose & 0.075 & 一 & 0.001 & - \\
\hline Succinate & 0.087 & $0 \cdot 101$ & 0.009 & $0 \cdot 109$ \\
\hline Fumarate & 0.475 & $1 \cdot 129$ & $0 \cdot 121$ & 0.397 \\
\hline Malate & $0 \cdot 387$ & - & 0.095 & 0.477 \\
\hline Nutrient broth & 0.222 & $0 \cdot 146$ & 0 & 一 \\
\hline
\end{tabular}

-, Not tested.

\section{Enzyme activities in mutants of the thermophile}

The activities of certain enzymes in extracts of acetate-grown cultures of wild-type cells and of mutants PC-2 and NG-15 are shown in Table 1. Isocitrate lyase and malate synthase activities were similar in all three organisms. Only extracts derived from the wild-type strain contained pyruvate carboxylase activity.

Extracts of mutant NG-15 contained considerably less NADP $^{+}$-dependent isocitrate dehydrogenase activity than those of the wild-type strain or of its mutant PC-2. No NAD ${ }^{+}-$ dependent isocitrate dehydrogenase was detected in any of the organisms.

Assays with mixed extracts of strains PC-2 and NG-15 showed that the low activities of the NADP ${ }^{+}$-dependent isocitrate dehydrogenase in extracts of the mutant NG-15 did not result from the presence of other inhibitors in the extract. The lack of isocitrate dehydrogenase activity in the mutant was, therefore, due to a genetic lesion.

Aconitase activity in extracts of strain NG-15 was higher than those of wild-type and strain PC-2 extracts. This agreed with the findings of Rutberg \& Hoch (1970), who showed that mutants lacking isocitrate dehydrogenase had enhanced aconitase activities.

The specific activity of isocitrate dehydrogenase in extracts of NG-15 that had been grown on carbon sources other than acetate was consistently lower than that found in similar extracts of wild-type and PC-2 cultures (Table 3). However, appreciable amounts of isocitrate dehydrogenase were synthesized by NG-15 when grown on malate or fumarate.

\section{Isocitrate concentrations in the mutant of the thermophile}

The isocitrate concentrations of extracts of the wild-type thermophile after growth on acetate, and on acetate in the presence of glucose, were 16.2 and $6.6 \mu \mathrm{mol}$ (g dry mass cells $)^{-1}$, respectively. Similarly, the values for the mutant NG-15 were 24.6 and $15 \cdot 7 \mu \mathrm{mol}$ (g dry mass cells) $)^{-1}$. (These results are the average for four individual extracts from two different cultures.) The concentrations of isocitrate in extracts of strain NG-15 were considerably higher than in similar extracts of wild-type cells. The increase appeared to be a consequence of the reduced ability of strain NG-15 to channel isocitrate through the $\mathrm{NADP}^{+}$-dependent isocitrate dehydrogenase.

\section{Glyoxylate concentrations in the mutant of the thermophile}

The glyoxylate concentrations in extracts of the wild-type organism grown on acetate averaged $1.3 \mu \mathrm{mol}$ (g dry mass cells) ${ }^{-1}$. The glyoxylate concentration in strain NG-15 extracts grown on the same carbon source was $0.8 \mu \mathrm{mol}$ (g dry mass cells) ${ }^{\mathbf{1}}$. 


\section{Revertants from NG-15 capable of good growth on glucose}

A culture of mutant NG-15 grown on acetate was plated on to salts/glucose plates, and the larger colonies which appeared after incubation at $55^{\circ} \mathrm{C}$ for between 24 and $36 \mathrm{~h}$ were removed and streaked on to fresh glucose plates. Single colony isolates were obtained and extracts of these mutants were assayed for pyruvate carboxylase activity. Fourteen of the colonies tested in this way had regained pyruvate carboxylase activity. Further examination of nine of these revertants showed that, whereas they synthesized isocitrate lyase normally during growth on acetate as sole carbon source, they had lost the ability to synthesize the enzyme when grown on acetate in the presence of glucose. These mutants had also regained the ability to synthesize wild-type levels of $\mathrm{NADP}^{+}$-dependent isocitrate dehydrogenase activity. The properties of one such revertant, designated R-9, are shown in the Tables; it is evident that the revertant had regained all the characteristics of the wild-type organism. It thus appears that the unusually high activities of isocitrate lyase observed when mutant NG-15 was grown on substrates other than acetate are directly related to the decreased activity of isocitrate dehydrogenase and the concomitantly increased concentrations of isocitrate.

\section{DISCUSSION}

Organisms growing on glucose as the sole carbon source fix $\mathrm{CO}_{2}$ with a $\mathrm{C}_{3}$-acid as an anaplerotic reaction. In the wild-type strain of a thermophilic Bacillus, $\mathrm{CO}_{2}$ was fixed into oxaloacetate via pyruvate carboxylase (Cazzulo et al., 1970). Mutant PC-2 which was devoid of pyruvate carboxylase was, therefore, unable to grow on glucose as the sole carbon source (Sundaram, 1973). However, mutant PC-2 grew normally on acetate with the 'induction' of isocitrate lyase being unimpaired. Addition of glucose to acetate-grown cells of mutant PC-2 inhibited growth because $\mathrm{C}_{3}$ compounds repressed and inhibited isocitrate lyase (Kornberg \& Smith, 1969). Mutant NG-15 was unusual in that it giew on acetate in the presence of glucose, although it was devoid of pyruvate carboxylase activity. Indeed, it grew on glucose alone, albeit poorly (Griffiths, 1974). This suggested that the regulation of isocitrate lyase synthesis, or control of its activity, must be different in this strain. Mutant NG-15 is similar to mutant NG-35 studied by Chell \& Sundaram (1975) in that both can grow on acetate in the presence of glucose, despite their lack of pyruvate carboxylase activity. There are, however, some notable differences between the two mutants. Mutant NG-35 is constitutive for isocitrate lyase as the enzyme is synthesized in cells grown on all media tested (Sundaram, 1973; Chell \& Sundaram, 1975). Although strain NG-15 also synthesizes isocitrate lyase on all media tested (Table 2), the activity of the enzyme in nutrient broth cultures is the same as that of the parent organism PC-2 which is not constitutive for the enzyme. The activity of isocitrate lyase in extracts of mutant NG-35 grown on nutrient broth is about 10 times greater than the activity in extracts of mutant NG-15 grown on the same medium (Table 2). Also, the isocitrate lyase activity in extracts of NG-35 grown on acetate appears to be about 2.5 times that of similar extracts of wild-type, PC-2 and NG-15. Thus strain NG-15 may not be truly constitutive for isocitrate lyase synthesis. This would indicate that there was an altered induction system for isocitrate lyase in mutant NG-15 or, alternatively, that there was a lack of inhibition of the isocitrate lyase from the mutant NG-15 by $\mathrm{C}_{3}$ compounds. The latter did not appear to be the case as the enzymes from the wild-type strain and mutant NG-15 were both inhibited by phosphoenolpyruvate and/or pyruvate.

Mutant NG-15 was also characterized by very low activities of NADP ${ }^{+}$-dependent isocitrate dehydrogenase during growth on all media examined. Extracts of NG-35 also have lower activities of $\mathrm{NADP}^{+}$-dependent isocitrate dehydrogenase than the wild-type organism, although not as low as mutant NG-15 (Chell \& Sundaram, 1975). The activity of this enzyme is still appreciable in strain NG-35 grown in nutrient broth. In contrast, there is no 
detectable isocitrate dehydrogenase activity in extracts of strain NG-15 grown in nutrient broth. Synthesis of the NADP ${ }^{+}$-dependent isocitrate dehydrogenase in the wild-type organism was repressed during growth on acetate and this agrees with the findings of Bennett \& Holms (1975).

Another difference between mutants NG-15 and NG-35 is that NG-35 grows much more slowly than the wild-type organism on acetate (relative growth rate of 0.26 ) (Chell \& Sundaram, 1975) whereas on the same carbon source NG-15 grows at the same rate as the wild-type organism. This slow growth of mutant NG-35 may be due to a deficiency of glutamate (Chell \& Sundaram, 1975) being caused by glyoxylate and oxaloacetate inhibiting and repressing isocitrate dehydrogenase. The build up of glyoxylate or a metabolite resembling it in mutant NG-35 has been reported by these authors. However no such build up of glyoxylate was observed in mutant NG-15 during growth on acetate, although the concentrations of isocitrate in mutant NG-15 were much higher than those in the wild-type organism grown under the same conditions. This suggested that the residual isocitrate dehydrogenase activity served to supply the glutamate needed for growth of mutant NG-15, but was not adequate for the supply of energy and anaplerotic intermediates. Hence, isocitrate lyase was needed to play this role and clearly this would not be possible unless the regulatory system for isocitrate lyase synthesis had been altered. It was not clear whether the lack of isocitrate dehydrogenase was necessarily associated with this altered isocitrate lyase regulation. One possibility was that the accumulation of isocitrate (or possibly citrate) might have induced the synthesis of isocitrate lyase in mutant NG-15. This hypothesis was supported by the finding that the wild-type strain of the thermophile synthesized isocitrate lyase to a considerable extent during poor growth on citrate. Ashworth \& Kornberg (1964) demonstrated that $E$. coli W could produce up to $30 \%$ of the activity of isocitrate lyase found in acetate-grown cells during growth on substrates that allowed only slow growth; in contrast, a mesophilic strain of Bacillus, B. licheniformis, also grew slowly on citrate, but without the synthesis of isocitrate lyase. Moreover, other organisms which grow on citrate, such as Salmonella sp., do not synthesize the enzyme on this medium (Kornberg, 1966). Isocitrate has been proposed as an inducer of isocitrate lyase in Neurospora crassa (Flavell \& Woodward, 1971) and it may be that isocitrate can act in this manner in cells of the thermophilic strain of Bacillus.

The possibility exists that the lesion in mutant NG-15 occurs in the gene specifying the synthesis of isocitrate dehydrogenase, whereas the mutation of strain NG-35 of Chell \& Sundaram (1975) is in the system regulating the synthesis of the glyoxylate cycle enzymes. However, the nature of these lesions remains unclear.

I thank Dr T. K. Sundaram for the gift of mutants PC-2 and NG-35 and the Medical Research Council for support through a postgraduate studentship. Sincere gratitude is expressed to Sir Hans Kornberg, F.R.S., for invaluable advice and discussion throughout this investigation.

\section{REFERENCES}

Ashworth, J. M. \& KornberG, H. L. (1964). The role of isocitrate lyase in Escherichia coli. Biochimica et biophysica acta 89, 383-384.

BenNeTt, P. M. \& Holms, W. H. (1975). Reversible inactivation of the isocitrate dehydrogenase of Escherichia coli ML308 during growth on acetate. Journal of General Microbiology 87, 37-51.

Cazzulo, J. J., Sundaram, T. K. \& Kornberg, H. L. (1970). Properties and regulation of pyruvate carboxylase from Bacillus stearothermophilus. Proceedings of the Royal Society B176, 1-19.

Chell, R. M. \& Sundaram, T. K. (1975). Mutants of Bacillus stearothermophilus de-repressed for isocitrate lyase and malate synthase. Biochemical Society Transactions 3, 306-309.

Cleland, W. W., Thompson, V.W. \& Barden, R. E. (1969). Isocitrate dehydrogenase (TPNspecific) from pig heart. Methods in Enzymology 13, 30-33.

Dixon, G. H. \& Kornberg, H. L. (1959). Assay methods for key enzymes of the glyoxylate cycle. Biochemical Journal 72, 3P.

EpSTEIN, I. \& Grossowicz, N. (1969). Prototrophic thermophilic Bacillus: isolation, properties and 
kinetics of growth. Journal of Bacteriology 99, 414-417.

Flavell, R. B. \& Woodward, D. O. (1971). Metabolic role, regulation of synthesis, cellular location and genetic control of the glyoxylate cycle enzymes in Neurospora crassa. Journal of Bacteriology 105, 200-210.

GRIFFITHS, M. W. (1974). The biochemistry of thermophilic micro-organisms. Ph.D. thesis, University of Leicester.

Griffiths, M. W. \& Sundaram, T. K. (1973). Isocitrate lyase from a thermophilic Bacillus: effect of salts on enzyme activity. Journal of Bacteriology 116, 1160-1169.

HARRIS, P. \& KorNBerG, H. L. (1972). The uptake of glucose by a thermophilic Bacillus sp. Proceedings of the Royal Society B182, 159-170.

Herman, N. J. \& Bell, E. J. (1970). Metabolic control in Acinetobacter sp. I. Effect of $\mathrm{C}_{4}$ versus $\mathrm{C}_{2}$ and $\mathrm{C}_{3}$ substrates on isocitrate lyase synthesis. Canadian Journal of Microbiology 16, 769-774.

Higgins, I. J. \& Sariaslani, F. S. (1973). Control of isocitrate lyase in Nocardia salmonicolor (NCIB 9701). Proceedings of the Society for General Microbiology 1, 21-22.

John, P. C. L. \& SyretT, P. J. (1968). The inhibition, by intermediary metabolites, of isocitrate lyase from Chlorella pyrenoidosa. Biochemical Journal 110, 481-484.

KLOTZSCH H. \& BeRgMeYer, H.-U. (1965). Glyoxylic acid. In Methods of Enzymatic Analysis, pp. 300-302. Edited by H.-U. Bergmeyer. New York \& London: Verlag Chemie/Academic Press.

KoRnBERG, H. L. (1965). Control of biosynthesis from $\mathrm{C}_{2}$ compounds. Colloques internationaux $d u$ Centre national de la recherche scientifique 124, 193-207.

KoRnBERG, H. L. (1966). The role and control of the glyoxylate cycle in Escherichia coli. Biochemical Journal 99, 1-11.

KornberG, H. L. \& KREBS, H. A. (1957). Synthesis of cell constituents from $\mathrm{C}_{2}$-units by a modified tricarboxylic acid cycle. Nature, London 179, 988991.
Kornberg, H. L. \& Madsen, N. B. (1957). Synthesis of $\mathrm{C}_{4}$-dicarboxylic acids from acetate by a 'glyoxylate bypass' of the tricarboxylic acid cycle. Biochimica et biophysica acta 24, 651-653.

KornberG, H. L. \& MADSEN, N. B. (1958). The metabolism of $\mathrm{C}_{2}$-compounds in micro-organisms. 3 . Synthesis of malate from acetate via the glyoxylate cycle. Biochemical Journal 68, 549-557.

KORNBERG, H. L. \& SMith, J. (1969). Genetic control of hexose phosphate uptake by Escherichia coli. Nature, London 224, 1261-1262.

Lowry, O. H., Rosebrough, N. J., FARr, A. L. \& RANDALL R. J. (1951). Protein measurement with the Folin phenol reagent. Journal of Biological Chemistry 193, 265-275.

LoWry, O. H., CARTer, J., WARd, J. B. \& Glaser, L. (1971). The effect of carbon and nitrogen sources on the level of metabolic intermediates in Escherichia coli. Journal of Biological Chemistry 246, 6511-6521.

MONOD, J. (1956). Remarks on the mechanism of enzyme induction. In Enzymes: Units of Biological Structure and Function, pp. 7-28. Edited by O. H. Gaebler. New York: Academic Press.

RACKER, E. (1950). Spectrophotometric measurements of the enzymatic formation of fumaric and cis-aconitic acids. Biochimica et biophysica acta 4, 211-214.

RutberG, B. \& HосH, J. A. (1970). Citric acid cycle: gene-enzyme relationships in Bacillus subtilis. Journal of Bacteriology 104, 826-833.

Sundaram, T. K. (1973). Physiological role of pyruvate carboxylase in a thermophilic Bacillus. Journal of Bacteriology 113, 549-557.

Sundaram, T. K. \& KornberG, H. L. (1969). Kinetic parameters of mesophilic and thermophilic isocitrate lyase. Journal of General Microbiology 55, xvii.

Sundaram, T. K., Cazzulo, J. J. \& Kornberg, H. L. (1969). Anaplerotic $\mathrm{CO}_{2}$ fixation in mesophilic and thermophilic bacilli. Biochimica et biophysica acta 192, 355-357. 